\title{
Diaphragmatic Excursion is Correlated With the Improvement in Exercise Tolerance After Pulmonary Rehabilitation in Patients With Chronic Obstructive Pulmonary Disease
}

Masashi Shiraishi ( $\square$ masashi-shiraishi@med.kindai.ac.jp )

Kindai University School of Medicine https://orcid.org/0000-0001-5410-1331

Yuji Higashimoto

Kindai University School of Medicine

Ryuji Sugiya

Kindai University School of Medicine

Hiroki Mizusawa

Kindai University School of Medicine

\section{Yu Takeda}

Kindai University School of Medicine

Shuhei Fujita

Kindai University School of Medicine

Osamu Nishiyama

Kindai University School of Medicine

\section{Shintarou Kudo}

Morinomiya University of Medical Sciences

\section{Tamotsu Kimura}

Kindai University School of Medicine

\section{Yasutaka Chiba}

Kindai University School of Medicine

Kanji Fukuda

Kindai University School of Medicine

Yuji Tohda

Kindai University School of Medicine

Hisako Matsumoto

Kindai University School of Medicine

Research 
Keywords: pulmonary rehabilitation, diaphragmatic excursion, COPD, six-minute walk distance

Posted Date: July 26th, 2021

DOI: https://doi.org/10.21203/rs.3.rs-704683/v1

License: (c) (1) This work is licensed under a Creative Commons Attribution 4.0 International License. Read Full License 


\section{Abstract}

Background: In patients with chronic obstructive pulmonary disease (COPD), the maximum level of diaphragm excursion $\left(\mathrm{DE}_{\max }\right)$ is correlated with dynamic lung hyperinflation and exercise tolerance. This study aims to clarify the utility of $D E_{\max }$ to predict the improvement in exercise tolerance after pulmonary rehabilitation (PR) in patients with COPD.

Methods: This was a prospective cohort study. Sixty-two patients with stable COPD participated in an outpatient PR programme from April 2018 to February 2021, and 50 completed the programme. Sixminute walk distance (6MWD) was used to evaluate exercise tolerance, and ultrasonography was used to measure $D E_{\max }$. Responders to $P R$ in exercise capacity were defined as patients with an increase $>30 \mathrm{~m}$ in $6 \mathrm{MWD}$. The receiver operating characteristic $(\mathrm{ROC})$ curve was used to determine the cut-off point of $D E_{\max }$ to predict responses to $P R$.

Results: Baseline levels of forced expiratory volume in one second $\left(\% \mathrm{FEV}_{1}\right), 6 \mathrm{MWD}$, maximum inspiratory pressure $\left(\mathrm{PI}_{\max }\right), D E_{\max }$ and quadriceps muscle strength (QMS) were significantly higher, and peak dyspnoea of modified Borg ( $\mathrm{mBorg}$ ) scale was lower in responders $(\mathrm{n}=30)$ than in non-responders $(\mathrm{n}=$ $20)$ to $P R(p<0.01)$. In multivariate analysis, $D E_{\max }$ was significantly correlated with an increase of $>30$ $\mathrm{m}$ in $6 \mathrm{MWD}$. The area under the ROC curve of $D E_{\max }$ to predict responders was 0.915 , with a sensitivity of $83 \%$ and a specificity of $95 \%$ at a cut-off point of $44.9 \mathrm{~mm}$ of $D E_{\max }$.

Conclusion: $\mathrm{DE}_{\max }$ well predicted the improvement in exercise tolerance after PR in patients with COPD.

\section{Summary Of Take-home Message}

Greater diaphragmatic excursion is an excellent predictor of the improvement in exercise tolerance by pulmonary rehabilitation (PR) and may help in identifying good responders to PR.

\section{Introduction}

Chronic obstructive pulmonary disease (COPD) is a progressive disease characterised by minimally reversible airflow limitation [1]. The main feature of COPD is the inability of patients to cope with their activities of daily life due to shortness of breath. Although the pathophysiological mechanisms involved in the development of dyspnoea and poor exercise tolerance in patients with COPD are complex, dynamic lung hyperinflation (DLH) plays a central role [2] by increasing ventilatory workload and decreasing the pressure-generating capacity of the inspiratory muscles.

Pulmonary rehabilitation (PR) is a non-pharmacological intervention and has been reported to improve dyspnoea, exercise capacity and quality of life in patients with COPD [3]. Owing to a body of evidence, PR is now established as the standard of care in patients with COPD [4]. However, not all patients with COPD 
benefit from PR to the same extent. Therefore, identifying patients who are likely to achieve maximum benefit from the PR programme is crucial. So far, several studies have shown that severe airflow limitation or poor exercise tolerance at baseline may predict a better response to PR $[5,6]$, but inconsistent findings are reported by others [7]. Furthermore, one study reported that patients with severe dyspnoea did not respond to PR and patients with milder dyspnoea responded well [8].

Considering the role of DLH in the development of dyspnoea and poor exercise tolerance in patients with COPD, objective measures that reflect DLH may help in identifying good responders to PR. Previously, we reported that there was an association between increased dyspnoea due to DLH on exercise and decreased exercise capacity in patients with COPD and reduced mobility of the diaphragm, which was assessed by the maximum level of diaphragm excursion $\left(\mathrm{DE}_{\mathrm{max}}\right)$ using ultrasonography [9]. Other research groups reported the utility of ultrasonographical assessment of diaphragmatic mobility in COPD on its association with 6-min walk distance (6MWD), dyspnoea [10] and increased mortality [11].

However, there have been no reports on the association between diaphragmatic mobility and the effect of $P R$ to improve exercise tolerance. The primary aim of this study is to clarify the role of $D E_{\max }$ to predict the improvement in exercise tolerance after PR in patients with COPD.

\section{Materials And Methods}

\section{Study Design and Subjects}

This was a single-centre, observational, prospective cohort study. The study included 62 patients with clinically stable COPD who visited the Department of Respiratory Medicine and Allergology, Kindai University Hospital, between April 2018 and February 2021. The exclusion criteria included unstable medical conditions that could cause or contribute to breathlessness, such as metabolic, cardiovascular or other respiratory diseases, or any other disorders that could interfere with exercise testing, such as neuromuscular diseases or musculoskeletal problems. This study was approved by the Ethics Committee of Kindai University School of Medicine. Written informed consent was obtained from all participants.

\section{Measurements}

Ultrasonography (Xario 200, Toshiba, Tokyo, Japan) was performed to all participants to measure their $\mathrm{DE}_{\mathrm{max}}$. Using the liver as an acoustic window (Figure $1 \mathrm{~A}$ ), a convex $3.5 \mathrm{MHz}$ probe was used to measure the excursions of the right hemidiaphragm according to the techniques in previous research $[9,12,13]$. The M-mode cursor was rotated and placed on the axis of diaphragmatic displacement on the stored image, and displacement measurements were conducted. Measurements were performed during each of three deep breaths, and $\mathrm{DE}_{\max }$ was measured (Figure 1B). The maximum value in the three deep breaths was used. 6MWD was used to evaluate walking capacity according to the ATS/ERS statement [14-16]. All participants performed the 6MWD test before and after the PR programme, and the magnitude of their perceived breathlessness and their leg fatigue was rated using a 1-10-point Borg scale. Responders to 
PR in exercise capacity were defined as those having more than $30 \mathrm{~m}$ increase in $6 \mathrm{MWD}$ after the PR programme, which was the definition of minimal clinically important difference (MCID) for 6MWD [17].

Spirometry (CHESTAC-800, Chest, Tokyo, Japan) was performed following the 2005 ATS/ERS recommendations [18] for measuring forced vital capacity (FVC), forced expiratory volume in one second $\left(\mathrm{FEV}_{1}\right)$ and inspiratory capacity. Respiratory muscle strength was assessed by measuring the maximum inspiratory pressure $\left(\mathrm{PI}_{\max }\right)$ generated against an occluded airway at residual volume [19] (SP-370, Fukuda Denshi, Tokyo, Japan). A hand-held dynamometer ( $\mu$ TasF-1, Anima Corp., Tokyo) was used to measure quadriceps muscle strength (QMS). The impact of COPD on health status was assessed with the COPD assessment test (CAT), a patient-completed questionnaire on eight items, namely, cough, phlegm, chest tightness, breathlessness, limited activities, confidence leaving home, sleeplessness and energy. The item scores range from 0 to 5 points, resulting in a CAT total score ranging from 0 to 40 points [20], and MCID of CAT is 2 points [21]. In all patients with COPD, emphysema was evaluated by computed tomography of the chest. A SYNAPSE VINCENT volume analyser (FUJIFILM Medical, Tokyo, Japan) was used to measure the low attenuation area (\%LAA).

\section{Rehabilitation Programme}

The outpatient PR programme was conducted twice a week for 12 weeks (24 sessions), including aerobic exercise training (ergometer and walking exercise) at $60 \%-70 \%$ of peak workload for $20-40$ min and upper- and lower-limb muscle strength training for 10-20 min.

\section{Sample Size}

The sample size was estimated using R software. The analysis based on $6 \mathrm{MWD}$ data from the PR programme revealed that 40 subjects were required if the expected area under the curve (AUC) below the receiver operating characteristic (ROC) curve was 0.80 , the power was $90 \%$, and the significance level was 0.01. Furthermore, we anticipated a dropout from the PR programme. Thus, we set the sample size to 50 participants.

\section{Statistical Analysis}

Responders and non-responders were compared using $t$-test, the Wilcoxon rank-sum test or $\chi^{2}$ test, as appropriate. The paired $t$-test or the Wilcoxon signed-rank test was used to evaluate the changes of the parameters before and after the PR programme. The Pearson correlation coefficient was used to analyse the relationships between changes in 6MWD and independent variables as changes in 6MWD were normally distributed. Additionally, multivariate logistic regression models were used to assess the ability of variables to predict a response to PR. The ROC curve method was used to assess the ability of $D E_{\max }$ to predict a response to PR. All statistical analyses were performed using the JMP software programme (JMP®, Version 14; SAS Institute Inc., Cary, NC, USA). 


\section{Result}

Out of the 62 patients included in the study, 50 completed the PR programme (Figure 2). Two patients dropped out because of severe exacerbation of COPD, and 10 patients discontinued the PR because of the coronavirus pandemic. Table 1 presents the baseline characteristics of the participants. After the PR programme, CAT score, 6MWD, peak dyspnoea and leg fatigue of modified Borg (mBorg) scale, and QMS improved significantly (Table 2). Thirty patients had an increase of $>30 \mathrm{~m}$ in 6MWD after PR (responders: $60 \%$ ), and 20 patients (40\%) were defined as non-responders. Baseline levels of $\% \mathrm{FEV}_{1}$, $6 \mathrm{MWD}, \mathrm{PI}_{\max }, \mathrm{DE}_{\max }$ and QMS were significantly higher and CAT score and peak dyspnoea of mBorg scale were significantly lower in responders than in non-responders (Table 1). Changes in $6 \mathrm{MWD}$ were significantly correlated with baseline levels of CAT, \%FEV ${ }_{1}$, peak dyspnoea of $\mathrm{mBorg}$ scale, $\mathrm{PI}_{\max }, \mathrm{DE}_{\max }$ (Figure 3) and QMS and marginally with baseline 6MWD (Table 3).

In multivariate analysis, $\mathrm{DE}_{\max }$ alone significantly contributed to the prediction of responders (Table 4, Model 1). When using $\mathrm{PI}_{\max }$ instead of $\mathrm{DE}_{\max }$ as $\mathrm{PI}_{\max }$ and $\mathrm{DE}_{\max }$ showed a strong association $(\mathrm{r}=0.73)$, both $\mathrm{PI}_{\max }$ and \%FEV 1 contributed to the prediction (Table 4, Model 2). The area under the ROC curve of $D E_{\max }$ to predict the responders was 0.915 , with a sensitivity of $83 \%$ and a specificity of $95 \%$ at a cutoff point of $44.9 \mathrm{~mm}$ of $D E_{\max }$ (Figure 4). The significance of $D E_{\max }$ in the predictability of responders remained even when the analysis was confined to severe patients $\left(\% \mathrm{FEV}_{1}<50 \%, \mathrm{n}=23 ; \mathrm{AUC}=0.88\right.$, sensitivity $=70 \%$ and specificity $=100 \%$ at a cut-off point of $44.9 \mathrm{~mm}$ ).

\section{Discussion}

This is the first study to show the utility of $D E_{\max }$ to predict the responsiveness to 12-week PR in patients with COPD. In this study, multivariate analysis revealed that greater baseline $\mathrm{DE}_{\max }$ was the only factor that predicted the responsiveness to PR, independent of baseline \%FEV $\mathrm{F}_{1}$. Additionally, the model using $D E_{\max }$ had better prediction performance than the model using $\mathrm{PI}_{\max }$. The $A U C$ of $D E_{\max }$ to predict the 30 m or more improvement in 6MWD after the PR was 0.915 , with a sensitivity of $83 \%$ and a specificity of $95 \%$ at $44.9 \mathrm{~mm}$.

PR is beneficial for patients with chronic respiratory disease, including COPD [3], and improves exercise performance, health-related quality of life and dyspnoea generally [22], which was confirmed in this study. Ideally, PR was proved to be effective in all patients, but the response to PR varies considerably between individual patients [8,23-25]. Indeed, in this study, the improvement in 6MWD was less than MCID in $40 \%$ of the patients irrespective of the degree of severity of COPD. Therefore, identifying predictors of a response is crucial in ensuring better PR efficacy and personalisation of PR programmes for patients with COPD. 
In this study, the baseline values of \% $\mathrm{FEV}_{1}, \mathrm{PI}_{\max }, \mathrm{DE}_{\mathrm{max}}, \mathrm{QMS}$ and 6MWD were positively associated with $\triangle 6 \mathrm{MWD}$ in univariate analysis, suggesting that a better baseline condition was related to a higher proportion of patients who gained the MCID after PR. These findings are consistent with those of previous studies that showed that patients with higher $\% \mathrm{FEV}_{1}$ or $\mathrm{FEV}_{1} / \mathrm{VC}$ achieved greater improvement in 6MWD after PR $[7,26,27]$ and a study in which patients with milder mMRC scores could achieve MCID of 6MWD after PR, but not for those with worst mMRC score [8], although others studies showed opposite results $[5,6,28-30]$ or found no significant baseline characteristics to predict a response to PR [31]. The discrepancy between the findings cannot be fully explained, but it might be due to the differences in the studied population and strength or length of PR. In this study, the mean \%FEV 1 of the participants was $56.0 \%$, which was relatively higher than that of other studies (mean $\% F V_{1}$ of $40-50 \%$ in most studies), despite similar inclusion criteria throughout the studies, that is, not limited to severe COPD in most studies. It can be said that no ceiling effect with a PR programme that included high-intensity load exercise training for 20-40 min was observed in our population.

In this study, an important finding is that greater $\mathrm{DE}_{\mathrm{max}}$ at baseline was the only factor that predicted the responders in 6MWD after PR. Additionally, the model using $\mathrm{DE}_{\mathrm{max}}$ had better prediction performance than the model using $\mathrm{PI}_{\max }$. The high predictability of $\mathrm{DE}_{\max }$ may be due to its strong association with DLH and dyspnoea during exercise, as reported previously [9]. DLH is involved in the development of dyspnoea, and both are important factors to determine the improvement in 6MWD in patients with COPD. Therefore, $D E_{\max }$ that reflects the degree of DLH and dyspnoea during exercise was superior to other physiological indices to predict responders.

Furthermore, the virtuous cycle observed in our PR programme that included high-intensity load exercise training might be due to the improvement in ventilation pattern. It would be easier to improve the ventilation pattern with greater $\mathrm{DE}_{\max }$, as shown in studies of mechanically ventilated patients [32], which may have reduced dyspnoea during exercise after 12 weeks of PR and improved exercise tolerance. Exercise therapy is a central component of $\mathrm{PR}$, which significantly reduces blood lactate levels during exercise, reduces minute ventilation and improves exercise tolerance [33]. The high-intensity load exercise training, which is performed at $60-80 \%$ of the maximum oxygen uptake, has a higher physiological effect than low exercise load. Patients with greater $D E_{\max }$ may be able to perform higher load training, which resulted in effective PR.

Diaphragm ultrasonography has been widely and successfully used to identify diaphragmatic dysfunction by showing its association with 6MWD, dyspnoea [10], extubation failure in mechanically ventilated patients [32] and increased mortality [11]. Recently, Lewinska and Shahnazzaryan proposed its use in pulmonary physiotherapy of patients with COPD [34]. In most of the previous studies, diaphragm ultrasonography was used to assess $\mathrm{DE}_{\text {max }}$, that is, the measurement of the excursion of the right hemidiaphragm, as used in this study, and diaphragm thickness that assessed the length and thickness of the zone of apposition of the diaphragm against the rib cage [35, 36]. However, diaphragm thickness is difficult to be measured in patients with severe COPD because the length of the zone of apposition is 
shorter in patients with COPD than in control subjects [37], whereas $\mathrm{DE}_{\max }$ is easy to be measured and shows high intra- and inter-observer reliability [38]. In clinical settings, this objective measure of $D E_{\max }$ has additional advantages as it requires minimum effort in patients and can be applied to the PR programme at home if portable ultrasonography can be used.

There are some limitations to this study. This was a single-centre study on a relatively small number of participants, and their baseline condition might be relatively preserved. Nonetheless, $46 \%$ of the participants showed $\mathrm{FEV}_{1}<50 \%$, and the utility of $\mathrm{DE}_{\max }$ was also observed in these patients with severe airflow limitation. Furthermore, in this study, few patients discontinued the PR programme, except for patients who discontinued during the coronavirus pandemic, which indicates that there was no severe mismatch between the PR programme and patients' ability to successfully complete the PR programme. Further studies with a large number of patients are required, and the utility of $D E_{\max }$ should be examined in patients with severest COPD with a low-intensity load exercise programme.

In conclusion, $\mathrm{DE}_{\mathrm{max}}$, which is a reliable and easy to perform measure, well predicted the improvement in exercise tolerance after $P R$ in patients with COPD. Assessment of $D E_{\max }$ may help in making medical decisions related to therapeutic strategies.

\section{Abbreviations}

COPD: Chronic obstructive pulmonary disease, DLH: dynamic lung hyperinflation, PR: Pulmonary rehabilitation, 6MWD: 6-min walk distance, MCID: minimal clinically important difference, FVC: forced vital capacity, $\mathrm{FEV}_{1}$ : forced expiratory volume in one second, $\mathrm{PI}_{\max }$ : maximum inspiratory pressure, QMS: quadriceps muscle strength, CAT : COPD assessment test, \%LAA : low attenuation area, AUC : area under the curve, ROC: receiver operating characteristic, mBorg: modified Borg

\section{Declarations}

\section{Support statement}

This work was supported by Grants-in-Aid for Scientific Research (21K11325).

\section{Acknowledgements}

Not applicable.

\section{Authors' contributions}

M.S. Y.H. and Y.C. made substantial contributions to the conception and design of the work. M.S., Y.H., R.S. made substantial contributions to the data acquisition. M.S. and H.M. made substantial contributions to the analysis. All of the listed authors designed the study and were involved in the 
interpretation of the data. M.S. and H.M. drafted the work. Y.H., M.S., T.K., Y.C., O.N., K.S., K.F., Y.T., H.M. revised the report critically for important intellectual content. All authors approved the final version to be published and agreed to be accountable for all aspects of the work.

\section{Funding}

This work was supported by Grants-in-Aid for Scientific Research (21K11325).

Availability of data and materials

The datasets used and/or analyzed during the current study are available from the corresponding author on reasonable request.

Consent for publication

Not applicable.

Competing interests

The authors declare no competing interests.

\section{References}

1. Global initiative for chronic obstructive lung disease (gold). Global strategy for the diagnosis, management, and prevention of chronic obstructive pulmonary disease: 2020 report. . https://goldcopd.org/gold-reports/last accessed: 20 Jan 2020.

2. Gagnon P, Guenette JA, Langer D, Laviolette L, Mainguy V, Maltais F, Ribeiro F, Saey D: Pathogenesis of hyperinflation in chronic obstructive pulmonary disease.International Journal of COPD 2014, 9:187-201.

3. Spruit MA, Singh SJ, Garvey C, ZuWallack R, Nici L, Rochester C, Hill K, Holland AE, Lareau SC, Man WD, et al: An official American Thoracic Society/European Respiratory Society statement: key concepts and advances in pulmonary rehabilitation.Am J Respir Crit Care Med 2013, 188:e13-64.

4. Dong J, Li Z, Luo L, Xie H: Efficacy of pulmonary rehabilitation in improving the quality of life for patients with chronic obstructive pulmonary disease: Evidence based on nineteen randomized controlled trials.International Journal of Surgery 2020, 73:78-86.

5. Boutou AK, Tanner RJ, Lord VM, Hogg L, Nolan J, Jefford H, Corner EJ, Falzon C, Lee C, Garrod R, et al: An evaluation of factors associated with completion and benefit from pulmonary rehabilitation in COPD.BMJ Open Respir Res 2014, 1:e00051.

6. Costi S, Crisafulli E, Trianni L, Beghe B, Faverzani S, Scopelliti G, Chetta A, Clini E: Baseline Exercise Tolerance and Perceived Dyspnea to Identify the Ideal Candidate to Pulmonary Rehabilitation: A Risk Chart in COPD Patients.Int J Chron Obstruct Pulmon Dis 2019, 14:3017-3023. 
7. van Ranst $\mathrm{D}$, Otten $\mathrm{H}$, Meijer JW, van 't Hul AJ: Outcome of pulmonary rehabilitation in COPD patients with severely impaired health status.Int J Chron Obstruct Pulmon Dis 2011, 6:647-657.

8. Garrod R, Marshall J, Barley E, Jones PW: Predictors of success and failure in pulmonary rehabilitation.Eur Respir J 2006, 27:788-794.

9. Shiraishi M, Higashimoto Y, Sugiya R, Mizusawa H, Takeda Y, Fujita S, Nishiyama O, Kudo S, Kimura T, Chiba $Y$, et al: Diaphragmatic excursion correlates with exercise capacity and dynamic hyperinflation in COPD patients.ERJ Open Res 2020, 6.

10. Paulin E, Yamaguti WPS, Chammas MC, Shibao S, Stelmach R, Cukier A, Carvalho CRF: Influence of diaphragmatic mobility on exercise tolerance and dyspnea in patients with COPD.Respir Med 2007, 101:2113-2118.

11. Yamaguti WPdS, Paulin E, Salge JM, Chammas MC, Cukier A, de Carvalho CRF: Diaphragmatic dysfunction and mortality in patients with COPD.Jornal Brasileiro de Pneumologia 2009, 35:1174-1181.

12. Boussuges A, Gole Y, Blanc P: Diaphragmatic motion studied by m-mode ultrasonography: methods, reproducibility, and normal values. Chest 2009, 135:391-400.

13. Testa A, Soldati G, Giannuzzi R, Berardi S, Portale G, Gentiloni Silveri N: Ultrasound M-Mode assessment of diaphragmatic kinetics by anterior transverse scanning in healthy subjects. Ultrasound Med Biol 2011, 37:44-52.

14. Laboratories ATSCoPSfCPF: ATS statement: guidelines for the six-minute walk test.Am J Respir Crit Care Med 2002, 166:111-117.

15. Holland AE, Spruit MA, Troosters T, Puhan MA, Pepin V, Saey D, McCormack MC, Carlin BW, Sciurba FC, Pitta F, et al: An official European Respiratory Society/American Thoracic Society technical standard: field walking tests in chronic respiratory disease.Eur Respir J 2014, 44:1428-1446.

16. Singh SJ, Puhan MA, Andrianopoulos V, Hernandes NA, Mitchell KE, Hill CJ, Lee AL, Camillo CA, Troosters T, Spruit MA, et al: An official systematic review of the European Respiratory Society/American Thoracic Society: measurement properties of field walking tests in chronic respiratory disease.Eur Respir J 2014, 44:1447-1478.

17. Polkey MI, Spruit MA, Edwards LD, Watkins ML, Pinto-Plata V, Vestbo J, Calverley PMA, Tal-Singer R, Agustí A, Bakke PS, et al: Six-Minute-Walk Test in Chronic Obstructive Pulmonary Disease.American Journal of Respiratory and Critical Care Medicine 2013, 187:382-386.

18. Miller MR, Hankinson J, Brusasco V, Burgos F, Casaburi R, Coates A, Crapo R, Enright P, van der Grinten CP, Gustafsson P, et al: Standardisation of spirometry.Eur Respir J 2005, 26:319-338. 
19. Lisboa C, Munoz V, Beroiza T, Leiva A, Cruz E: Inspiratory muscle training in chronic airflow limitation: Comparison of two different training loads with a threshold device.Eur Respir J 1994, 7:1266-1274.

20. Jones PW, Harding G, Berry P, Wiklund I, Chen WH, Kline Leidy N: Development and first validation of the COPD Assessment Test.Eur Respir J 2009, 34:648-654.

21. Kon SSC, Canavan JL, Jones SE, Nolan CM, Clark AL, Dickson MJ, Haselden BM, Polkey MI, Man WDC: Minimum clinically important difference for the COPD Assessment Test: a prospective analysis. The Lancet Respiratory Medicine 2014, 2:195-203.

22. Lacasse Y, Goldstein R, Lasserson TJ, Martin S: Pulmonary rehabilitation for chronic obstructive pulmonary disease.Cochrane Database Syst Rev 2006:CD003793.

23. Spruit MA, Gosselink R, Troosters T, Kasran A, Van Vliet M, Decramer M: Low-grade systemic inflammation and the response to exercise training in patients with advanced COPD.Chest 2005, 128:3183-3190.

24. de Torres JP, Pinto-Plata V, Ingenito E, Bagley P, Gray A, Berger R, Celli B: Power of outcome measurements to detect clinically significant changes in pulmonary rehabilitation of patients with COPD.Chest 2002, 121:1092-1098.

25. Troosters T, Gosselink R, Decramer M: Exercise training in COPD: how to distinguish responders from nonresponders.J Cardiopulm Rehabil 2001, 21:10-17.

26. Vagaggini B, Costa F, Antonelli S, De Simone C, De Cusatis G, Martino F, Santerini S, Paggiaro P: Clinical predictors of the efficacy of a pulmonary rehabilitation programme in patients with COPD.Respir Med 2009, 103:1224-1230.

27. Scott AS, Baltzan MA, Fox J, Wolkove N: Success in pulmonary rehabilitation in patients with chronic obstructive pulmonary disease.Can Respir J 2010, 17:219-223.

28. Crisafulli E, Gorgone P, Vagaggini B, Pagani M, Rossi G, Costa F, Guarriello V, Paggiaro P, Chetta A, de Blasio F, et al: Efficacy of standard rehabilitation in COPD outpatients with comorbidities.Eur Respir J 2010, 36:1042-1048.

29. Zanini A, Chetta A, Gumiero F, Della Patrona S, Casale S, Zampogna E, Aiello M, Spanevello A: SixMinute Walking Distance Improvement after Pulmonary Rehabilitation Is Associated with Baseline Lung Function in Complex COPD Patients: A Retrospective Study.BioMed Research International 2013, 2013:16.

30. Ragaselvi S, Janmeja AK, Aggarwal D, Sidana A, Sood P: Predictors of response to pulmonary rehabilitation in stable chronic obstructive pulmonary disease patients: A prospective cohort study.J Postgrad Med 2019, 65:101-106. 
31. Selzler A-M, Simmonds L, Rodgers WM, Wong EYL, Stickland MK: Pulmonary Rehabilitation in Chronic Obstructive Pulmonary Disease: Predictors of Program Completion and Success.COPD: Journal of Chronic Obstructive Pulmonary Disease 2012, 9:538-545.

32. Li C, Li X, Han H, Cui H, Wang G, Wang Z: Diaphragmatic ultrasonography for predicting ventilator weaning: A meta-analysis.Medicine (Baltimore) 2018, 97:e10968.

33. Rabinovich RA, Ardite E, Troosters T, Carbo N, Alonso J, Gonzalez de Suso JM, Vilaro J, Barbera JA, Polo MF, Argiles JM, et al: Reduced muscle redox capacity after endurance training in patients with chronic obstructive pulmonary disease.Am J Respir Crit Care Med 2001, 164:1114-1118.

34. Lewinska A, Shahnazaryan K: The Use of Diaphragm Ultrasonography in Pulmonary Physiotherapy of COPD Patients: A Literature Review.J Clin Med 2020, 9.

35. Gibson GJ, Whitelaw W, Siafakas N, Supinski GS, Fitting JW, Bellemare F, Loring SH, Troyer AD, Grassino AE: ATS/ERS Statement on respiratory muscle testing.Am J Respir Crit Care Med 2002, 166:518624.

36. Summerhill EM, El-Sameed YA, Glidden TJ, McCool FD: Monitoring recovery from diaphragm paralysis with ultrasound. Chest 2008, 133:737-743.

37. McKenzie DK, Butler JE, Gandevia SC: Respiratory muscle function and activation in chronic obstructive pulmonary disease.J Appl Physiol 2009, 107:621-629.

38. Laveneziana P, Albuquerque A, Aliverti A, Babb T, Barreiro E, Dres M, Dubé BP, Fauroux B, Gea J, Guenette JA, et al: ERS statement on respiratory muscle testing at rest and during exercise.Eur Respir J 2019, 53.

\section{Tables}

Due to technical limitations, table 1-4 is only available as a download in the Supplemental Files section.

\section{Figures}



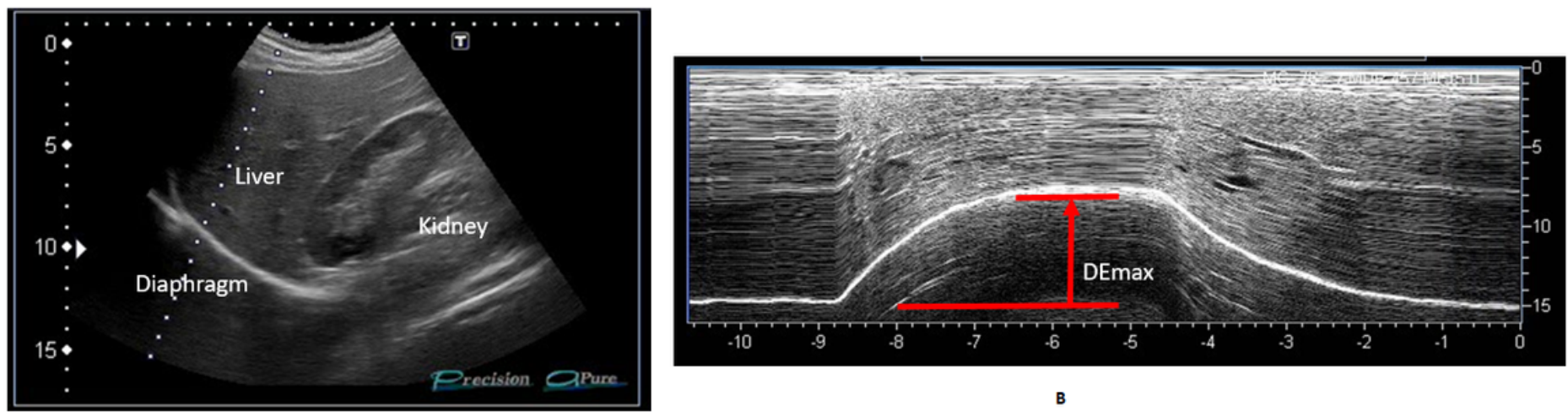

A

\section{Figure 1}

Representative image of the right diaphragm. The probe was positioned below the right costal margin between the midclavicular and anterior axillary lines. (A) Two-dimensional ultrasonographic image of the right hemidiaphragm (B-mode). Diaphragmatic movements were recorded in M-mode during deep breathing (DEmax) (B).

\section{Figure 2}

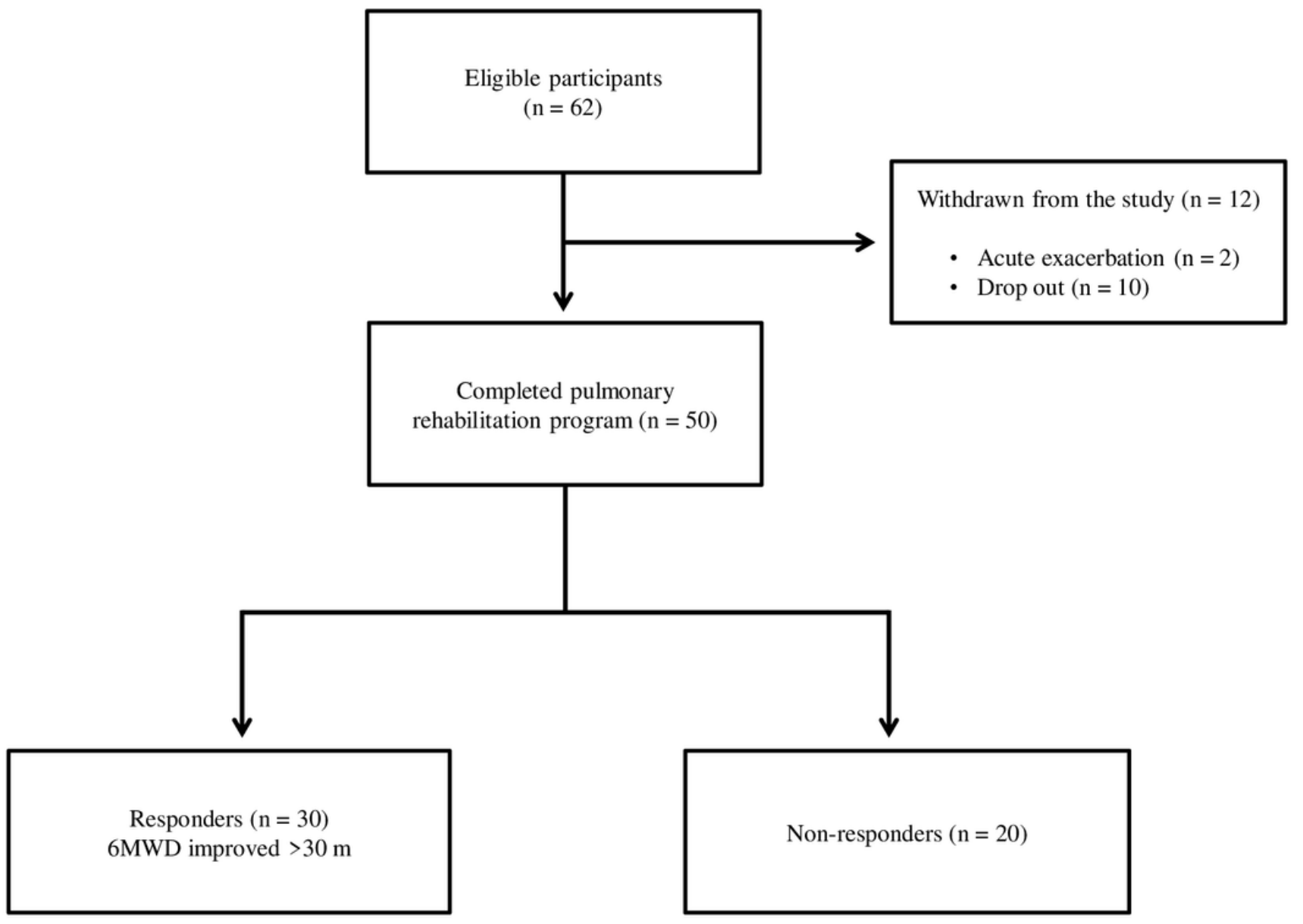


Figure 2

Study flow diagram. COPD: chronic obstructive pulmonary disease; PR: pulmonary rehabilitation; 6MWD: 6-min walk distance.

Figure 3

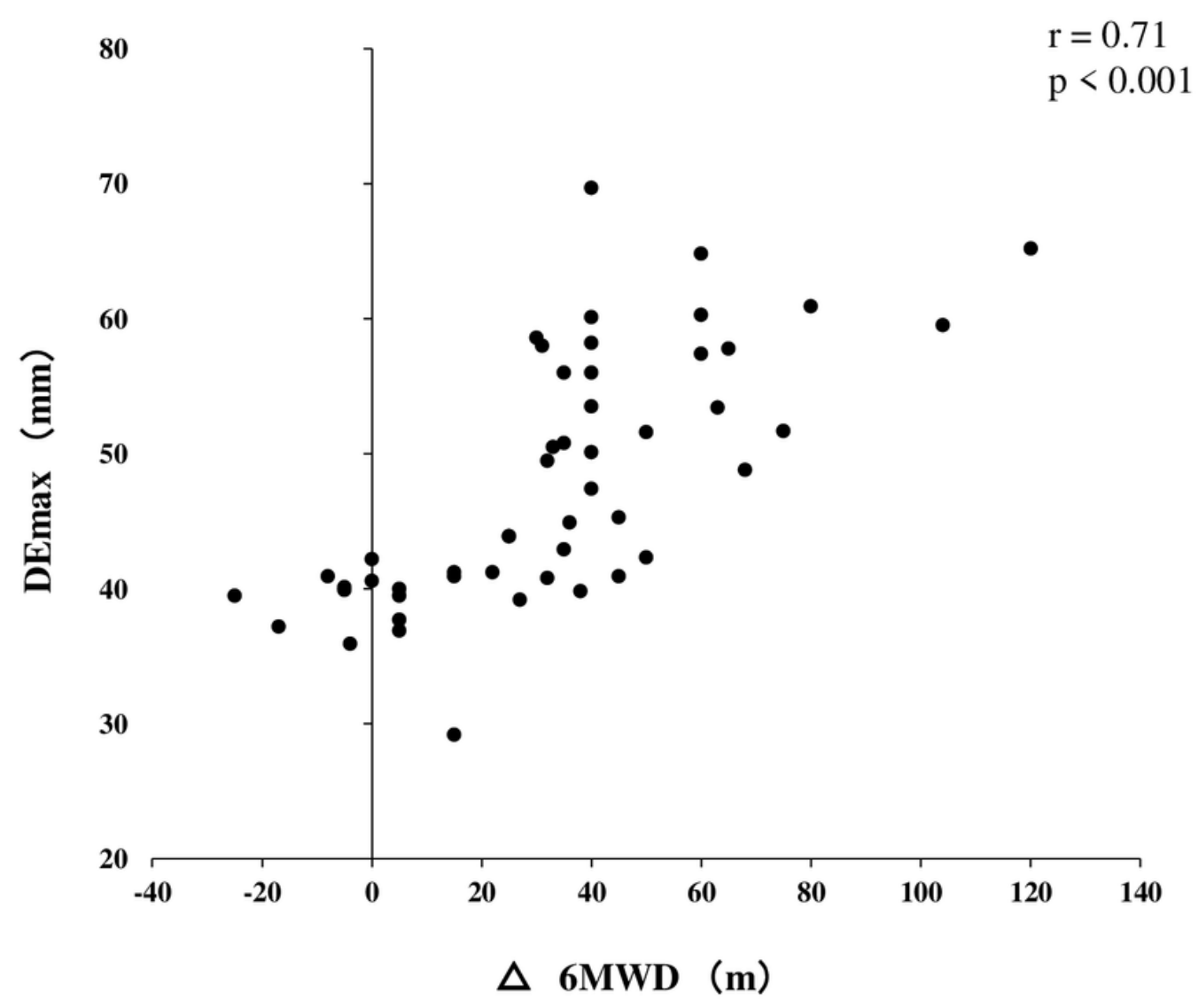

Figure 3

Relationship between DEmax and the changes in 6MWD after pulmonary rehabilitation. Changes in 6 MWD were significantly positively correlated with DEmax $(r=0.72 ; p<0.001)$. DEmax: maximum diaphragmatic excursion; 6MWD: 6-min walk distance. 
Figure 4

\section{ROC curve}

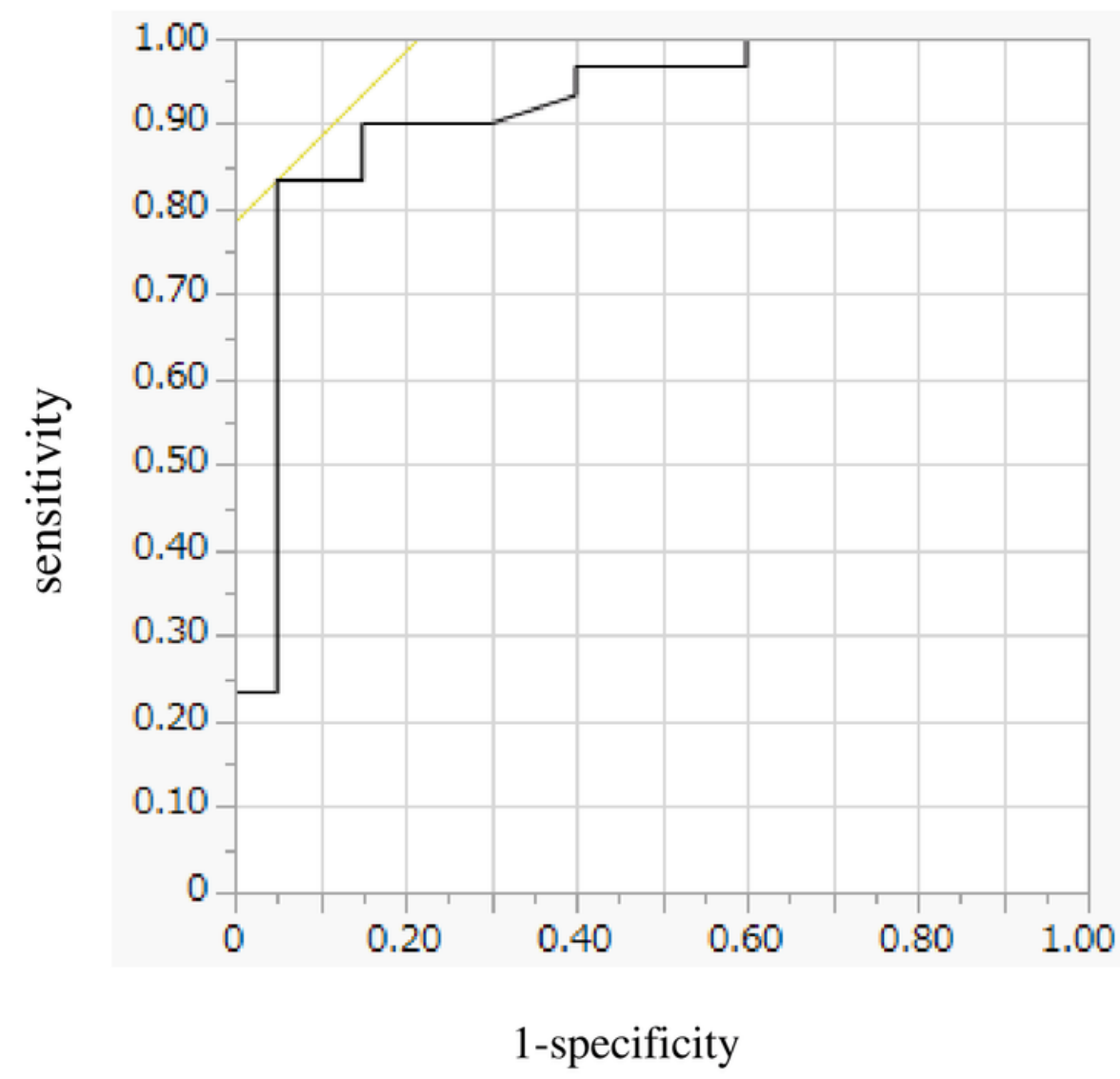

Figure 4

Receiver operating characteristic (ROC) curve for baseline DEmax in relation to the response to pulmonary rehabilitation. ROC curve estimates the ability of DEmax to predict a clinically important improvement in 6MWD $(>30 \mathrm{~m})$ after pulmonary rehabilitation (AUC $=0.915$, sensitivity $=83 \%$ and specificity $=95 \%$ at a cut-off point of $44.9 \mathrm{~mm}$ of DEmax). AUC: area under the curve; 6MWD: 6-min walk distance; DEmax: maximum diaphragmatic excursion.

\section{Supplementary Files}

This is a list of supplementary files associated with this preprint. Click to download.

- Tables.pdf 